\title{
Previously Identified Common Post-Injury Adverse Events in Traumatic Spinal Cord Injury-Validation of Existing Literature and Relation to Selected Potentially Modifiable Comorbidities: A Prospective Canadian Cohort Study
}

\author{
Travis E. Marion,, Carly S. Rivers,2 Dilnur Kurban,2 Christiana L. Cheng,2 Nader Fallah,2 Juliet Batke, \\ Marcel F. Dvorak, ${ }^{1}$ Charles G. Fisher, ${ }^{1}$ Brian K. Kwon, Vanessa K. Noonan, ${ }^{2}$ and John T. Street ${ }^{1}$
}

\begin{abstract}
Adverse events (AEs) are common during care in patients with traumatic spinal cord injury (tSCI). Increased risk of AEs is linked to patient factors including pre-existing comorbidities. Our aim was to examine the relationships between patient factors and common post-injury AEs, and identify potentially modifiable comorbidities. Adults with tSCI admitted to a Level I acute specialized spine center between 2006 and 2014 who were enrolled in the Rick Hansen SCI Registry (RHSCIR) and had AE data collected using the Spine Adverse Events Severity system were included. Patient demographic, neurological injury, and comorbidities data were obtained from RHSCIR. Potentially modifiable comorbidities were grouped into health-related conditions, substance use/withdrawal, and psychiatric conditions. Negative binomial regression and multiple logistic regression were used to model the impact of patient factors on the number of AEs experienced and the occurrence of the five previously identified common AEs, respectively. Of the 444 patients included in the study, $24.8 \%$ reported a health-related condition, $15.3 \%$ had a substance use/withdrawal condition, $8 \%$ reported having a psychiatric condition; and $79.3 \%$ experienced one or more AEs. Older age $(p=0.004)$ and more severe injuries $(p<0.001)$ were nonmodifiable independent variables significantly associated with increased AEs. The AEs experienced by patients were urinary tract infections $(42.8 \%)$, pneumonia (39.2\%), neuropathic pain $(31.5 \%)$, delirium (18.2\%), and pressure ulcers (11.0\%). Risk of delirium increased in those with substance use/withdrawal; and pneumonia risk increased with psychiatric comorbidities. Opportunity exists to develop clinical algorithms that include these types of risk factors to reduce the incidence and impact of AEs.
\end{abstract}

Keywords: adverse events; comorbidities; complications; spinal cord injury; Spine Adverse Events Severity system

\section{Introduction}

A FTER A TRAUMATIC SPINAL CORD INJURY (tSCI), patients often experience one or more adverse events (AEs) 1 -i.e., medical complications or secondary diagnoses, which are commonly referred to as secondary complications and can occur at any point after injury, such as during acute care, rehabilitation care, and throughout the rest of a person's life. Experiencing AEs during the period of initial hospitalization can disrupt care and negatively impact outcomes. ${ }^{2}$ Identifying persons who may be at an increased risk for experiencing $\mathrm{AEs}^{1-9}$ will help care providers pinpoint who may benefit the most from preventative interventions.
Patient factors have been shown to be associated with risk of specific AEs including urinary tract infections (UTI), ${ }^{2,7,10}$ pneumonia, ${ }^{2,7,11}$ delirium, ${ }^{2,7,12,13}$ and cardiac complications. ${ }^{10}$ Advancing age is a significant predictor for increased risk of AEs. ${ }^{1-9}$ Gender differences in AEs were also found, with males being at higher general risk of AEs, ${ }^{5,7}$ respiratory complications, ${ }_{10}^{10}$ and pressure ulcers (PU), ${ }^{14}$ and females at higher risk of UTI, ${ }^{10}$ delirium, ${ }^{7}$ and deep vein thrombosis. ${ }^{13}$

Injury factors such as high energy injury mechanisms, ${ }^{2,7}$ presence of injuries concurrent to SCI as measured by Injury Severity Score (ISS), ${ }^{6,11,15}$ Glasgow Coma Scale (GCS), ${ }^{10,16}$ or presence/ number of other major injuries ${ }^{7,10}$ have been shown to increase the

\footnotetext{
${ }^{1}$ Department of Orthopaedics, Vancouver Spine Surgery Institute, University of British Columbia, Vancouver, British Columbia, Canada.

${ }^{2}$ Rick Hansen Institute, Vancouver, British Columbia, Canada
}

(c) Travis E. Marion et al., 2017; Published by Mary Ann Liebert, Inc. This Open Access article is distributed under the terms of the Creative Commons Attribution Noncommercial License (http://creativecommons.org/licenses/by-nc/4.0/) which permits any noncommercial use, distribution, and reproduction in any medium, provided the original author(s) and the source are credited. 
risk of AEs. Severity of SCI, as measured by the International Standards for Neurological Classification of SCI (ISNCSCI), ${ }^{17}$ also affects risk of AEs because the anatomical region and the completeness of injury affect which body systems are disrupted and the motor and sensory impairment of the patient. More severe injuries and higher level injuries elevate the risk of AEs generally $8,11,16,18$ and specific types of AEs including pneumonia and other respiratory complications, ${ }^{11}$ autonomic dysreflexia, ${ }^{19} \mathrm{PU},{ }^{20}$ and pain. ${ }^{21}$

Increased risk of AEs in the general spine population has also been linked to the presence/number of comorbidities ${ }^{3-5}$ and higher Charlson ${ }^{18}$ and Elixhauser comorbidity index scores. ${ }^{6,15}$ Specific associations have been reported between: diabetes and cardiac complications, post-operative infections, hematoma, and risk of complications $^{22}$; previous smoking and complications ${ }^{16}$; anemia and respiratory complications ${ }^{10}$; psychiatric disorder and acute onset depression ${ }^{23}$; obesity and complications ${ }^{24}$; and pulmonary disease/infection and previous PU have been linked to risk of PU. ${ }^{25}$

Although there are many reported associations of comorbidities and AEs in the literature, there has been little focus on potentially modifiable comorbidities that, if appropriately managed, may reduce the risk of relevant AEs in acute care, saving both in costs and burden on patients. Using data from prospectively collected data sources, the objectives of this study were to: (1) validate existing interactions between patient factors (nonmodifiable factors) and AEs in the acute phase of SCI care; and (2) identify potentially modifiable comorbid conditions related to previously identified common AEs that may encourage future management strategies to reduce AE risk.

\section{Methods}

\section{Study design}

Adults with acute tSCI who were admitted to an acute specialized spine facility in a Level I trauma center (the study site, Vancouver General Hospital) and who were enrolled in the Rick Hansen SCI Registry (RHSCIR) and had AE data collected using the Spine Adverse Events Severity (SAVES) ${ }^{1,26}$ system, which may record no experienced AEs, were included in the study cohort (2006-2014). Prospective SAVES data collection was piloted in 2006 and implemented in 2008. The RHSCIR is a prospective observational database that collects data on adult patients who have sustained a new tSCI and are admitted to a participating site. The RHSCIR includes data extracted from patient chart review and linkage to hospital administration databases (using the International Classification of Diseases, Tenth Revision [ICD 10] coding system) ${ }^{27}$ from the Discharge Administration Database (DAD). Institutional Research Ethics Board approval was obtained before enrolling patients. Full details of the RHSCIR have been published elsewhere. ${ }^{28}$

Previously reported analyses on a smaller cohort of patients $(n=171)$ with SAVES data ${ }^{2}$ were repeated to validate the results on a larger sample in this study, which included the original sample. In keeping with the previous methodology established by Street and associates, ${ }^{2}$ analyses were performed to validate the most common AEs, and the association of top AEs found by Street and associates ${ }^{2}$ (delirium, pneumonia, neuropathic pain [NP], PU, UTI) and total number of AEs with patient and injury (nonmodifiable) factors. New analyses were performed to identify potentially modifiable comorbidities relating to these common AEs. Inclusion criteria included patients having both comorbidity and AE data. Patients admitted to the study site more than seven days post-injury were excluded.

\section{Study variables}

Age, gender, mechanism of injury (fall vs. nonfall), neurological severity and level of injury measured at admission by the American Spinal Injury Association (ASIA) Impairment Scale
(AIS) of the ISNCSCI ${ }^{17}$ were the nonmodifiable factors considered in the analyses.

Data on comorbidities collected for the RHSCIR were categorized to ensure that the same comorbidity was counted only once for the same patient. Count of comorbidities was calculated by summing all unique comorbidities of each patient.

Potentially modifiable comorbidities in the acute setting included: health-related conditions (hypertension, diabetes, Parkinson disease, multiple sclerosis, and epilepsy), substance (alcohol, drug) use/withdrawal, psychiatric conditions (delirium, schizophrenia, nonorganic psychosis, bipolar, depressive episode, mood disorder, anxiety, obsessive-compulsive [anankastic] personality disorder, history of self-harm, gender identity disorder). The comorbidities were grouped into the three categories (health-related conditions, substance use/withdrawal, and psychiatric conditions) based on their clinical symptoms and causes.

The AE data were obtained from the prospective, validated SAVES instrument used to collect AE data (type of AE if present, or absence of AE) during the inpatient stay at the study site. ${ }^{26}$ The SAVES instrument has been described in detail elsewhere. ${ }^{1,26}$ Where the same AE was recorded more than once for a patient, it was counted once. Count/number of AEs was calculated by summation of all unique AEs (main SAVES items) of each patient.

\section{Statistical analysis}

Descriptive statistics were used to describe patient and injury factors and the AEs. To determine the association between number of AEs experienced and nonmodifiable factors, a negative binomial regression model was applied with outliers removed based on the Tukey rule (i.e., $1.5 \times$ interquartile range rule). The association between each of the common five AEs experienced and nonmodifiable factors were modeled using multiple logistic regressions with a stepwise variable selection method ( $p$ values for a variable to enter and stay in the model set to 0.25 and 0.10 , respectively). Initial models included nonmodifiable factors such as age at injury, gender, mechanism of injury (fall; nonfall), AIS (AIS A; AIS B,C; AIS D) and neurological level (high cervical, C1-C4; low cervical, C5-T1; thoracic/thoracolumbar/lumbar/sacral, T2-S5) as covariates. Final models included statistically significant covariates but age, AIS and neurological level were included regardless of their statistical significance because they were considered to be clinically relevant.

Bivariate analyses were performed to test associations between AEs and potentially modifiable comorbidities using the $\chi^{2}$ test unless the expected counts were less than five, in which case the Fisher's exact test was performed. Bivariate associations were reexamined with multivariate logistic regressions to adjust for significant nonmodifiable risk factors of each AE identified from the final models. Age at injury, AIS and neurological level were always included because of their clinical significance.

Goodness of fit tests were performed for all models and Akaike Information Criterion was used for model selection. Associations with a $p$ value $<0.05$ were considered statistically significant. All analyses were performed using SAS software, Version 9.4 of the SAS System for Windows. ${ }^{\circ}$ 2013. SAS Institute Inc., Cary, NC.

\section{Results}

Of the 528 patients admitted to the study site between 2006 and 2014 with AE data collected, 52 were ineligible and 32 were eligible but excluded, leaving a final study cohort of 444 patients (Fig. 1). Table 1 describes the patient and injury factors of the study cohort.

The mean age of patients in the cohort was $47.5 \pm 20.3$ years, $79 \%$ were male, and $44 \%$ had fall-related injuries. Fifty-six percent of the patients had at least one reported comorbidity, and $13 \%$ had 


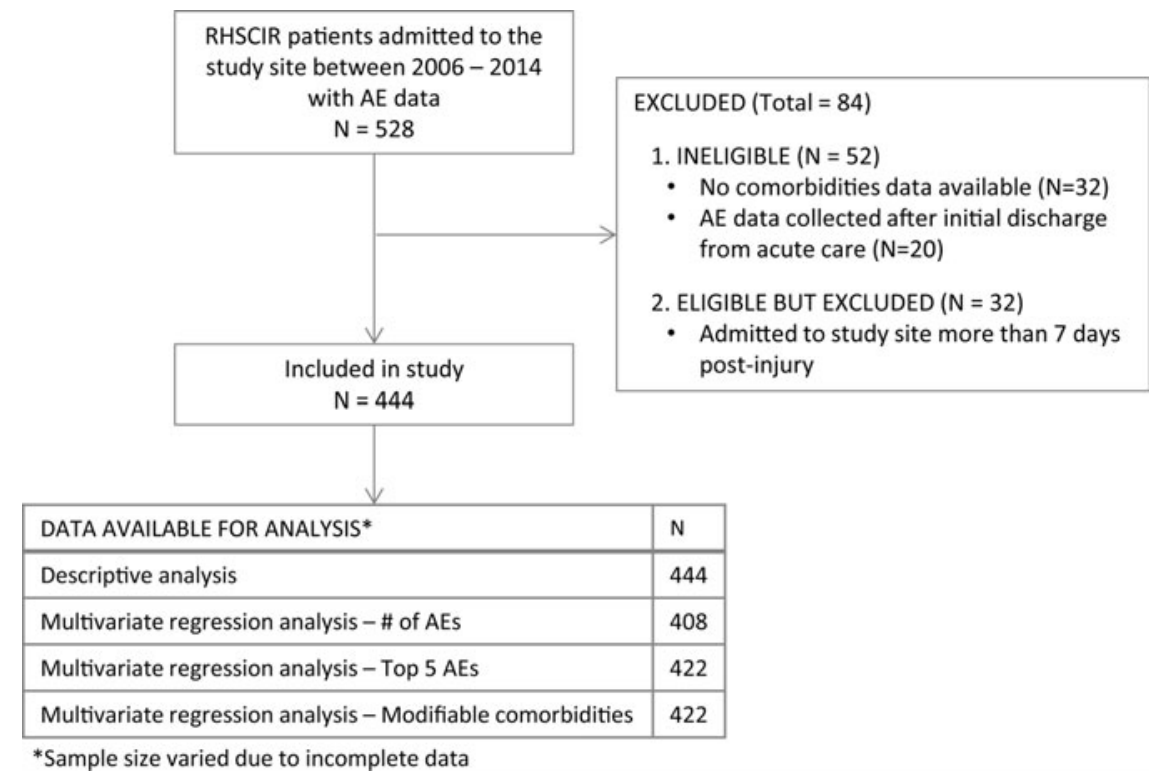

FIG. 1. Sample size flow chart for the study analysis. Collection of AE data with Spine Adverse Events Severity system was piloted in 2006 and implemented in 2008. RHSCIR, Rick Hansen Spinal Cord Injury Registry; AEs, adverse events.

Table 1. Patient Characteristics in the Study Cohort

\begin{tabular}{lc}
\hline Variable & Value \\
\hline Number of patients in study cohort & 444 \\
Age at injury; mean \pm SD & $47.5 \pm 20.3$ \\
Male gender; n (\%) & $352(79.3)$ \\
Mechanism of injury; n (\%) & \\
$\quad$ Falls & $189(44.4)$ \\
$\quad$ Non-falls & $237(55.6)$ \\
ASIA Impairment Scale (AIS); n (\%) & \\
AIS A & $167(39.4)$ \\
AIS B/C & $133(31.4)$ \\
AIS D & $124(29.2)$
\end{tabular}

Neurological level of injury; n (\%)

High cervical, C1-C4

Low cervical, C5-T1

Thoracic/thoracolumbar/lumbar/sacral, T2-S5

$139(32.5)$

$135(31.5)$

$154(36.0)$

Counts of comorbidities; $\mathrm{n}(\%)$

None

$195(43.9)$

$192(43.2)$

$57(12.8)$

Three or more

$110(24.8)$

$68(15.3)$

$35(7.9)$

$92(20.7)$

$183(41.2)$

$169(38.1)$

$8.5(4,16)$

Time from injury to admission to study site (hours); median (Q1,Q3) three or more. Of the potentially modifiable comorbidities, $25 \%$ of patients had a health-related condition, $15 \%$ had a substance use/ withdrawal condition, and $8 \%$ had a psychiatric condition. The incidence of comorbidities within each condition is listed in Table 2. Twenty-one percent of patients experienced no AE, 79\% experienced at least one $\mathrm{AE}$, and $38 \%$ of these had three or more.

\section{Nonmodifiable factors}

For incidence of AEs, older age and having a more severe injury (AIS A,B/C vs. AIS D) were significantly associated with experiencing more AEs (Table 3). Adjusting for age and injury severity, the number of AEs would increase by 1.006 for every year older $(p=0.004)$. Patients with AIS A or AIS B/C injuries would experience about two times more AEs compared with patients with AIS D injuries (2.2 times, 1.7 times, respectively; $p<0.0001)$. The 10 most common AEs observed were UTI, pneumonia, NP, delirium, cardiac arrest/failure/arrhythmia, dysphagia, systemic infection, PU, neurological deterioration, and superficial wound infection as

Table 2. Incidence of the Potentially MODIFIABle COMORBIDITIES

\begin{tabular}{clc} 
Group & \multicolumn{1}{c}{ Comorbidity } & Incidence (\%) \\
\hline Health-related & Hypertension & 20.0 \\
conditions & Diabetes & 10.8 \\
& Parkinson disease/multiple & 1.1 \\
Substance use/ & Alcohol use & \\
withdrawal & Drug use & 11.0 \\
& Withdrawal & 4.7 \\
Psychiatric & Schizophrenia & 3.6 \\
conditions & Depressive disorder & 0.9 \\
& Anxiety & 3.4 \\
& Other psychiatric & 2.7 \\
& conditions & 1.6 \\
\hline
\end{tabular}

*Health-related condition included hypertension, diabetes, Parkinson disease, multiple sclerosis, and epilepsy.

SD, standard deviation; ASIA, American Spinal Injury Association; Q1, first quartile; Q3, third quartile. 
Table 3. A Negative Binomial Regression to Model the Impact of Patient Characteristics on the Number of Adverse Events (AEs) Experienced

\begin{tabular}{|c|c|c|c|c|c|}
\hline \multirow[b]{2}{*}{ Independent variable } & \multirow[b]{2}{*}{ Estimate } & \multirow[b]{2}{*}{ Std. error } & \multicolumn{3}{|c|}{ Number of AEs experienced } \\
\hline & & & $95 \%$ Wald $C I$ & Estimate* & $\mathrm{p}$ \\
\hline Intercept & -0.18 & 0.13 & $-0.44-0.08$ & 0.84 & 0.1803 \\
\hline Age at injury & 0.006 & 0.002 & $0.002-0.01$ & 1.01 & 0.0038 \\
\hline \multicolumn{6}{|l|}{ ASIA Impairment Scale (AIS) } \\
\hline AIS A & 0.78 & 0.10 & $0.58-0.99$ & 2.19 & $<0.0001$ \\
\hline AIS B/C & 0.55 & 0.11 & $0.34-0.77$ & 1.74 & $<0.0001$ \\
\hline AIS D (reference) & - & - & - & - & - \\
\hline \multicolumn{6}{|l|}{ Neurological level of injury } \\
\hline High cervical, $\mathrm{C} 1-\mathrm{C} 4$ & 0.12 & 0.10 & $-0.07-0.32$ & 1.13 & 0.2172 \\
\hline Low cervical, $\mathrm{C} 5-\mathrm{T} 1$ & 0.15 & 0.10 & $-0.04-0.35$ & 1.17 & 0.1214 \\
\hline Thoracic/thoracolumbar/lumbar/sacral, T2-S5 (reference) & - & - & - & - & - \\
\hline
\end{tabular}

*Parameter estimates after exponentiation.

The number of AEs was calculated by summation of all unique AEs each patient had. Bold $p$ values indicate statistical significance.

CI, confidence interval; ASIA, American Spinal Injury Association.

shown in Table 4. Comparing the five AEs reported in the previous study, ${ }^{2}$ higher frequency was found in this study.

Individual multiple logistic regression models were used to determine patient factors (nonmodifiable risk factors) that affect the occurrence of the five AEs (Table 5). Adjusting for age, gender, AIS and neurological level, odds of developing a UTI increased by 1.01 for every year older (95\% CI [confidence interval] 1.0-1.02); females were twice as likely compared with males (95\% CI 1.3$3.5)$ to develop a UTI. Patients with AIS A or AIS B/C injuries were three times (95\% CI 1.8-5.3) and two times (95\% CI 1.2-3.4), respectively, more likely to develop a UTI compared with those with AIS D injuries (Table 5).

After adjusting for age, gender, AIS and neurological level, the odds of experiencing pneumonia were higher in males and in patients with more severe injuries or cervical injuries. Males were 1.9 times more likely compared with females (95\% CI 1.1-3.3) to develop pneumonia. Patients with AIS A or AIS B/C injuries were 12 times (95\% CI 6.2-22.3) or five times (95\% CI 2.6 9.2), respectively, more likely compared with those with AIS D injuries, and patients with cervical injuries were three times more likely than those with thoracic/thoracolumbar/lumbar/sacral injuries to develop pneumonia ( $p=0.0001)$ (Table 5).

The odds of developing delirium increased by 1.04 for one year increase in age $(p<0.0001)$. Males were three times more likely compared with females (95\% CI 1.4-7.7); and patients with AIS B/C were two times more likely compared with those with AIS D injuries (95\% CI 1.1-4.6) to develop delirium (Table 5).

For developing PU, the odds were 10 times (95\% CI 3-34) and five times (95\% CI 1.5-19) for patients with AIS A and AIS B/C injuries, respectively, compared with those with AIS D injuries. Patients with low cervical injuries were twice as likely to develop PU than those with thoracic/thoracolumbar/lumbar/sacral injuries (95\% CI 1.1-4.8) (Table 5). No patient or injury factors were significantly associated with development of NP.

\section{Potentially modifiable comorbidities}

Table 6 shows the association of potentially modifiable comorbidities for the five AEs previously identified by Street et al. ${ }^{2}$ According to the bivariate analyses, the modifiable comorbidities related to health-related conditions were significantly associated
Table 4. Incidence of Adverse Events

\begin{tabular}{|c|c|c|}
\hline Adverse event & $\begin{array}{l}\text { Analysis } \\
\text { cohort }(\%)\end{array}$ & $\begin{array}{c}\text { Street and } \\
\text { associates } \\
2015(\%)\end{array}$ \\
\hline Urinary tract infections & 42.8 & 32.2 \\
\hline Pneumonia & 39.2 & 32.8 \\
\hline Neuropathic pain & 31.5 & 15.2 \\
\hline Delirium & 18.2 & 18.7 \\
\hline Cardiac arrest/failure/arrhythmia & 15.3 & \\
\hline Dysphagia & 12.6 & \\
\hline Systemic infection & 12.2 & \\
\hline Pressure ulcers & 11.0 & 14.6 \\
\hline Neurological deterioration & 4.7 & \\
\hline Superficial wound infection & 4.7 & \\
\hline Pulmonary embolism & 3.6 & \\
\hline Hematoma & 3.4 & \\
\hline Deep wound infection & 3.2 & \\
\hline $\begin{array}{l}\text { Intra-op hardware malposition } \\
\text { requiring revision }\end{array}$ & 2.9 & \\
\hline Intra-op airway/ventilation & 2.3 & \\
\hline Intra-op dural tear & 2.3 & \\
\hline Deep vein thrombosis & 1.6 & \\
\hline Gastrointestinal bleeding & 1.4 & \\
\hline Dysphonia & 1.4 & \\
\hline Intra-op massive blood loss & 1.4 & \\
\hline Allergic reaction & 1.1 & \\
\hline Cerebrospinal fluid leak/meningocele & 1.1 & \\
\hline Wound dehiscence & 0.9 & \\
\hline Construct failure with loss of correction & 0.7 & \\
\hline Intra-op hypotension & 0.7 & \\
\hline $\begin{array}{l}\text { Hardware malposition } \\
\text { requiring revision }\end{array}$ & 0.5 & \\
\hline Myocardial infarction & 0.5 & \\
\hline $\begin{array}{l}\text { Bone implant interface } \\
\text { failure requiring revision }\end{array}$ & 0.2 & \\
\hline Dural tear & 0.2 & \\
\hline Intra-op allergic reaction & 0.2 & \\
\hline Intra-op cardiac & 0.2 & \\
\hline Intra-op cord injury & 0.2 & \\
\hline Intra-op nerve root injury & 0.2 & \\
\hline Massive blood loss & 0.2 & \\
\hline
\end{tabular}

Intra-op, intraoperative.

Where multiple incidents of a particular $\mathrm{AE}$ occur, the $\mathrm{AE}$ is only counted once per patient. 
Table 5. Logistic Regression Analyses to Explore Nonmodifiable Factors that Affect the Occurrence of the Adverse Events as Analyzed in Street and Associates

\begin{tabular}{|c|c|c|c|c|c|c|}
\hline Outcome & Independent variable & Estimate & Std. error & Odds ratio & $95 \%$ Wald CI & $\mathrm{p}$ \\
\hline \multirow[t]{13}{*}{ Urinary tract infections } & Intercept & -1.49 & 0.35 & - & - & $<0.0001$ \\
\hline & Age at injury & 0.01 & 0.005 & 1.01 & $1.0-1.02$ & $\mathbf{0 . 0 2 3 3}$ \\
\hline & Gender & & & & & \\
\hline & Female & 0.74 & 0.25 & 2.09 & $1.27-3.45$ & 0.0037 \\
\hline & Male (reference) & - & - & - & - & - \\
\hline & ASIA Impairment Sca & AIS) & & & & \\
\hline & AIS A & 1.13 & 0.27 & 3.09 & $1.84-5.20$ & $<0.0001$ \\
\hline & AIS B/C & 0.67 & 0.27 & 1.96 & $1.15-3.35$ & 0.0136 \\
\hline & AIS D (reference) & - & - & - & - & - \\
\hline & Neurological level of & & & & & \\
\hline & $\mathrm{C} 1-\mathrm{C} 4$ & -0.34 & 0.27 & 0.72 & $0.42-1.21$ & 0.2134 \\
\hline & $\mathrm{C} 5-\mathrm{T} 1$ & -0.34 & 0.26 & 0.71 & $0.42-1.19$ & 0.1901 \\
\hline & T2-S5 (reference) & - & - & - & - & - \\
\hline \multirow[t]{13}{*}{ Pneumonia } & Intercept & -3.03 & 0.42 & - & - & $<0.0001$ \\
\hline & Age at injury & 0.008 & 0.006 & 1.01 & $0.99-1.02$ & 0.1919 \\
\hline & Gender & & & & & \\
\hline & Female & -0.62 & 0.29 & 0.54 & $0.30-0.95$ & $\mathbf{0 . 0 3 4 0}$ \\
\hline & Male (reference) & - & - & - & - & - \\
\hline & ASIA Impairment Sca & AIS) & & & & \\
\hline & AIS A & 2.47 & 0.33 & 11.77 & $6.21-22.29$ & $<0.0001$ \\
\hline & AIS B/C & 1.60 & 0.32 & 4.93 & $2.63-9.24$ & $<0.0001$ \\
\hline & AIS D (reference) & - & - & - & - & - \\
\hline & Neurological level of & & & & & \\
\hline & $\mathrm{C} 1-\mathrm{C} 4$ & 1.15 & 0.30 & 3.18 & $1.75-5.77$ & 0.0001 \\
\hline & $\mathrm{C} 5-\mathrm{T} 1$ & 1.24 & 0.30 & 3.44 & $1.93-6.14$ & $<0.0001$ \\
\hline & T2-S5 (reference) & - & - & - & - & - \\
\hline \multirow[t]{13}{*}{ Delirium } & Intercept & -3.65 & 0.51 & - & - & $<0.0001$ \\
\hline & Age at injury & 0.04 & 0.007 & 1.04 & $1.02-1.05$ & $<0.0001$ \\
\hline & Gender & & & & & \\
\hline & Female & -1.20 & 0.44 & 0.30 & $0.13-0.71$ & 0.006 \\
\hline & Male (reference) & - & - & - & - & - \\
\hline & ASIA Impairment Sca & AIS) & & & & \\
\hline & AIS A & 0.50 & 0.36 & 1.64 & $0.81-3.33$ & 0.1676 \\
\hline & AIS B/C & 0.83 & 0.36 & 2.28 & $1.13-4.60$ & 0.0207 \\
\hline & AIS D (reference) & - & - & - & - & - \\
\hline & Neurological level of & & & & & \\
\hline & $\mathrm{C} 1-\mathrm{C} 4$ & -0.23 & 0.35 & 0.80 & $0.40-1.60$ & 0.518 \\
\hline & $\mathrm{C} 5-\mathrm{T} 1$ & -0.09 & 0.35 & 0.92 & $0.46-1.82$ & 0.8027 \\
\hline & T2-S5 (reference) & - & - & - & - & - \\
\hline \multirow[t]{10}{*}{ Pressure ulcers } & Intercept & -3.85 & 0.72 & - & - & $<0.0001$ \\
\hline & Age at injury & -0.006 & 0.008 & 0.99 & $0.98-1.01$ & 0.4921 \\
\hline & ASIA Impairment Sca & AIS) & & & & \\
\hline & AIS A & 2.31 & 0.63 & 10.11 & $2.97-34.40$ & 0.0002 \\
\hline & AIS B/C & 1.70 & 0.65 & 5.47 & $1.54-19.48$ & 0.0087 \\
\hline & AIS D (reference) & - & - & - & - & - \\
\hline & Neurological level of & & & & & \\
\hline & $\mathrm{C} 1-\mathrm{C} 4$ & 0.17 & 0.44 & 1.18 & $0.50-2.80$ & 0.7053 \\
\hline & $\mathrm{C} 5-\mathrm{T} 1$ & 0.82 & 0.38 & 2.27 & $1.08-4.78$ & 0.0314 \\
\hline & T2-S5 (reference) & - & - & - & - & - \\
\hline
\end{tabular}

Neuropathic pain model was not shown because it was not significant as a whole. Bold $p$ values indicate statistical significance.

Std. error, standard error; CI, confidence interval; ASIA, American Spinal Injury Association.

with NP and delirium; substance use/withdrawal was significantly associated with delirium; and psychiatric conditions were significantly associated with pneumonia and NP. After adjusting for age, AIS and neurological level, and gender if statistically significant from above, only the associations between psychiatric conditions and pneumonia and between substance use/withdrawal and delirium remained significant. Psychiatric conditions increased the odds of developing pneumonia by four times (95\% CI 1.6-10.5). Substance use/withdrawal conditions increased the odds of developing delirium by 2.5 times (95\% CI $1.3-4.8)$.

\section{Discussion}

Of the 444 patients studied, $79 \%$ experienced at least one $\mathrm{AE}$ and $38 \%$ experienced three or more, which correlates well with an earlier study using the SAVES instrument in which $77 \%$ of patients 
Table 6. Individual Multiple Logistic Regression Models to Explore the Association of the Adverse Events as Analyzed in Street and Associates and Each Group of Potentially Modifiable Comorbidity

\begin{tabular}{|c|c|c|c|c|c|c|c|}
\hline Outcome & Model & Independent variable & Estimate & Std. error & Odds ratio $*$ & $95 \%$ Wald CI & $\mathrm{p}^{*}$ \\
\hline \multirow[t]{3}{*}{ Urinary tract infections } & 1 & Health-related condition & -0.09 & 0.28 & 0.92 & $0.52-1.60$ & 0.7538 \\
\hline & 2 & Substance use/withdrawal & 0.28 & 0.28 & 1.32 & $0.76-2.28$ & 0.3256 \\
\hline & 3 & Psychiatric conditions & -0.31 & 0.39 & 0.73 & $0.34-1.58$ & 0.4276 \\
\hline \multirow[t]{3}{*}{ Pneumonia } & 1 & Health-related condition & 0.22 & 0.31 & 1.26 & $0.69-2.29$ & 0.4593 \\
\hline & 2 & Substance use/withdrawal & 0.41 & 0.30 & 1.50 & $0.83-2.72$ & 0.1811 \\
\hline & 3 & Psychiatric conditions & 1.41 & 0.48 & 4.08 & $1.59-10.51$ & 0.0035 \\
\hline \multirow[t]{3}{*}{ Delirium } & 1 & Health-related condition & 0.009 & 0.33 & 0.99 & $0.51-1.91$ & 0.9782 \\
\hline & 2 & Substance use/withdrawal & 0.93 & 0.32 & 2.54 & $1.34-4.80$ & 0.0042 \\
\hline & 3 & Psychiatric conditions & -0.30 & 0.54 & 0.74 & $0.26-2.16$ & 0.5847 \\
\hline \multirow[t]{3}{*}{ Pressure ulcers } & 1 & Health-related condition & -0.68 & 0.48 & 0.51 & $0.20-1.29$ & 0.1539 \\
\hline & 2 & Substance use/withdrawal & -0.51 & 0.50 & 0.60 & $0.22-1.61$ & 0.3102 \\
\hline & 3 & Psychiatric conditions & -0.54 & 0.64 & 0.58 & $0.17-2.07$ & 0.4042 \\
\hline
\end{tabular}

*Adjusted for age at injury, neurological severity (American Spinal Injury Association Impairment Scale) and level, and gender if statistically significant for the adverse event.

The absence of a particular potentially modifiable comorbidity was used as a reference for the comorbidity. Neuropathic pain models were not shown because they were not significant as a whole. Bold $p$ values indicate statistical significance.

Std. error, standard error; CI, confidence interval.

experienced at least one AE. ${ }^{2}$ Compared with that study, ${ }^{2}$ we found the most common AEs experienced were UTI, pneumonia, NP, delirium, and cardiac arrest/failure/arrhythmia, and similar nonmodifiable risk factors for developing an $\mathrm{AE}$ included age at time of injury, gender, and severity of injury. Potentially modifiable comorbidities including psychiatric conditions were associated with increased risk of pneumonia, while substance use/withdrawal conditions were associated with elevated risk of delirium.

\section{Relation to previous literature}

The literature reports lower rates of AEs, but these studies are retrospective in nature compared to the prospective SAVES method, which has demonstrated improved capture of AEs, twice as many when compared with chart extraction, and has excellent inter- and intraobserver reliability. ${ }^{8,26,29}$ Our study demonstrated a higher incidence of AEs than in the previous study by Street and colleagues $^{2}$ who also used the SAVES method (Table 4). A more rigorous schedule of SAVES data collection over time may explain the increase in reported AEs observed in this study.

In our study, older age and more severe injury were significant nonmodifiable risk factors for experiencing a higher number of any AEs. The association between AEs in older patients with tSCI has been described previously, $2,9,19$ with an earlier study finding an incidence of AEs in $57.1 \%$ of older patients compared to $33.3 \%$ in younger patients. ${ }^{30}$ Increased age was also correlated with risk of AEs in earlier work at the study site. ${ }^{7}$ In terms of injury severity, when neurologic function was assessed in previous studies, $33.5 \%$ of patients with incomplete injuries (AIS B/C/D) were reported to experience at least one $\mathrm{AE}$, compared with $59.5 \%$ of those with complete injuries (AIS A). ${ }^{30}$ Age and less severe initial AIS have been used in a recent clinical prediction model for long-term functional outcome after tSCI. ${ }^{31}$

The most common AEs identified in our study were UTI $(42.8 \%)$, pneumonia $(39.2 \%)$, NP (31.5\%), delirium (18.2\%), cardiac arrest/failure/arrhythmia $(15.3 \%)$, dysphasia (12.6\%), systemic infections (12.2\%), and PU (11\%), coinciding with previous literature that also reported high rates of cardiac complications and infections after SCI. ${ }^{10,19,30}$
Age, gender, injury severity and level identified in our study as nonmodifiable risk factors for experiencing the most common AEs were comparable with other studies. Interestingly, risk of PU was associated only with injury severity, a trend that was also observed in the earlier study in which motor score was used as a measure of injury severity. ${ }^{2}$ Injury severity has been consistently found to be a significant risk factor for $\mathrm{PU}^{11,25}$ and is one of the 18 predictive risk factors for PU in persons with SCI identified in a recent systematic review. ${ }^{32}$ Age and gender were not found to part of the key predictive risk factors for PU development, similar to our study. ${ }^{32}$

The finding that older age, being female, and having more severe injuries presents a higher risk factor for UTI reported in this study aligns with existing studies for the SCI population, ${ }^{10}$ as well as for the community-dwelling population in which UTI is found to be more common in older women, specifically those who are postmenopausal $^{33}$ revealing a possible biological mechanism underlying the development for UTI.

\section{Implications}

We aimed to identify potentially modifiable pre-existing comorbidities or conditions that are associated with acute AEs; the term "modifiable" is not intended to mean completely fixable, or preventative, rather potentially "managed" in hopes of reducing the impact of pre-existing conditions on AEs risk given the high frequency of AEs in the acute period. After adjusting for age, injury severity and level, and gender if statistically significant, substance use/withdrawal and psychiatric comorbidities were identified as potentially modifiable risk factors for AEs including delirium and pneumonia. Opportunity exists to develop clinical algorithms that include these types of risk factors to reduce the incidence and impact of AEs. Further, effort has been invested at our institution to identify and develop a multidisciplinary management strategy in response to our acute $\mathrm{AE}$ rate in patients with $\mathrm{tSCI}$. We anticipate that these initiatives will lead to a significant decrease in morbidity and length of stay associated with tSCI. ${ }^{2,7}$ A report of any early data regarding the impact of these interventions on potentially modifiable comorbidities is not within the scope of this study. 
Alcohol intoxication at time of injury has been identified in $20 \%$ of all tSCIs between 2000 and 2006 by the National Trauma Data Bank in the United States. ${ }^{34}$ Our study did not distinguish intoxication at the time of injury from substance (alcohol/drug) use or withdrawal. We did, however, identify substance use or withdrawal, considered to be potentially modifiable, as a significant risk factor for delirium. To our knowledge, this is the first study to report it as a risk factor for acute AEs in those with tSCI. This is of significant clinical importance because delirium has been shown to increase length of hospital stay, post-discharge institutionalization, long-term cognitive deficits, and mortality. ${ }^{12,35,36}$ Further, delirium will become an increasing problem because of advancing age at time of SCI. ${ }^{12}$ Although delirium is often multifactorial and difficult to detect, ${ }^{37,38}$ self-reported alcohol use has been established as a component of noncardiac surgery delirium risk scores. ${ }^{39}$ Early recognition and management of alcohol/drug use or withdrawal through multicomponent strategies of nursing interventions and pharmacological prophylaxis may mitigate its impact on acute AEs.

Our findings of psychiatric comorbidities identified as significant risk factors for pneumonia corroborate literature showing that antipsychotics use increases the risk of pneumonia, ${ }^{40}$ and that readmission within 30 days because of pneumonia is more common in persons with psychiatric comorbidities. ${ }^{41} \mathrm{Re}$ cognizing and managing psychiatric comorbidities after tSCI will be crucial especially for those who have multiple trauma and invasive medical procedures, which are common for SCI, because these factors have been shown to significantly increase the pneumonia incidence. ${ }^{42}$ Future studies examining the possible additive effect of these factors and psychiatric comorbidities on pneumonia deserve attention because pneumonia is the leading cause of death after acute $\mathrm{SCI}^{43}$ and is associated with poor neurological outcome, longer stay in hospital, and increased rate of discharge to a skilled nursing facility. ${ }^{44}$

\section{Next steps/gaps}

Results from this study will be applied to the Access to Care and Timing (ACT) simulation model of tSCI care ${ }^{45}$ to enhance the prediction of complications. Injury characteristics (ISS, GCS) that have been associated with AEs developing were not included in this study but are important to consider in future studies. Further investigation of the NP data will be needed because the NP models from the current analysis were not significant, making it difficult to examine its association with nonmodifiable and modifiable factors reliably. This might be attributed to the complexity of its pathogenesis and clinical diagnosis, and is consistent with the high heterogeneity in reporting the prevalence of NP concluded by a recent systematic review and meta-analysis. ${ }^{46}$

At the study site, a clinical protocol to screen, diagnose, and manage NP has been developed with a multidisciplinary team, ${ }^{47}$ and full implementation of the protocol will help improve clinical understanding and management of NP. Recognizing that risk of AEs is multifactorial, future work using network analysis is planned to explore the interactions between each top $\mathrm{AE}$ and various patient, neurological, functional, and clinical (comorbidities and other AEs) factors.

\section{Limitations}

This study does not report on intraoperative events or long-term outcomes because this was not the aim of this study. All patients received appropriate medical management of AEs upon their rec- ognition in keeping with standard medical practice. This study was set forth to (1) validate existing interactions between patient factors (nonmodifiable factors) and common AEs initially identified by Street and associates ${ }^{2}$ in the acute phase of SCI care; and (2) identify potentially modifiable comorbid conditions related to previously identified common AEs. It did not intend to investigate the management strategies of patient care with respect to comorbidities and the change in patient outcome.

The common AEs evaluated represent those identified by a preexisting study from a smaller sample. This does represent a limitation in that not all of the most common AEs from this study were assessed with the same scrutiny. Further, it does not consider all comorbidities such as smoking and anemia; the intent of the current study was to explore the relation of a selection of comorbidities and complications as a first step in exploring the possible opportunity to address potentially modifiable comorbidities to prevent or mitigate complications. Analysis of all comorbidities and complications would also likely introduce higher family-wise error rate because of performing multiple hypotheses tests.

The study site is a quaternary referral center with established protocols and multidisciplinary teams involved in all stages of patient care; however, being a single center may minimize the variability in patient factors, which could limit generalizability. Further, the rigorous prospective SAVES method is complex and resource intensive; this may not be feasible at all centers and therefore difficult to implement into practice. To facilitate the implementation of SAVES into practice, a shortened version of SAVES is being validated and may address this limitation.

\section{Conclusion}

We identified a substantially higher incidence of acute AEs in patients with tSCI compared with the literature; however, the most common AEs identified in this study are consistent with the literature. Age, gender, and injury severity were nonmodifiable risk factors for AEs. The focus of this article was to identify modifiable conditions relating to post-injury AEs in patients with tSCI; these included substance use/withdrawal and psychiatric conditions. Although not considered "fixable," this study suggests an opportunity to address potentially modifiable conditions associated with AEs. Future development of clinical algorithms that screen for these types of risk factors should be considered in the effort to reduce incidence of AEs.

\section{Acknowledgments}

The authors thank Elaine Chan for research support; the Vancouver Spine Research Program (Allan Aludino); the Rick Hansen Institute RHSCIR Team (Suzanne Humphreys, Daniel Rogers, Kristen Walden, Jayson Shurgold, Jessica Eapen, Jerome Buenaventura, Tova Plashkes, Arlene Aspinall, Cynthia Morin, and Shannon Sproule); and all members of the Vancouver Spine Surgery Institute for their support to the study.

This study was supported by financial contributions from the Rick Hansen Institute, the Ontario Neurotrauma Foundation, and the Government of Canada through Health Canada and Western Economic Diversification Canada.

\section{Author Disclosure Statement}

No competing financial interests exist. 


\section{References}

1. Rampersaud, Y.R., Neary, M.A., and White, K. (2010). Spine adverse events severity system: content validation and interobserver reliability assessment. Spine 35, 790-795.

2. Street, J.T., Noonan, V.K., Cheung, A., Fisher, C.G., and Dvorak, M.F. (2015). Incidence of acute care adverse events and long-term health-related quality of life in patients with TSCI. Spine J. 15, 923 932

3. Kalanithi, P.S., Patil, C.G., and Boakye, M. (2009). National complication rates and disposition after posterior lumbar fusion for acquired spondylolisthesis. Spine 34, 1963-1969.

4. Boakye, M., Patil, C.G., Santarelli, J., Ho, C., Tian, W., and Lad, S.P. (2008). Cervical spondylotic myelopathy: complications and outcomes after spinal fusion. Neurosurgery 62, 455-462.

5. Li, G., Patil, C.G., Lad, S.P., Ho, C., Tian, W., and Boakye, M. (2008). Effects of age and comorbidities on complication rates and adverse outcomes after lumbar laminectomy in elderly patients. Spine 33, $1250-1255$.

6. Boakye, M., Arrigo, R.T., Kalanithi, P.S., and Chen, Y.R. (2012) Impact of age, injury severity score, and medical comorbidities on early complications after fusion and halo-vest immobilization for $\mathrm{C} 2$ fractures in older adults: a propensity score matched retrospective cohort study. Spine 37, 854-859.

7. Glennie, R.A., Ailon, T., Yang, K., Batke, J., Fisher, C.G., Dvorak, M.F., Vaccaro, A.R., Fehlings, M.G., Arnold, P., Harrop, J.S., and Street, J.T. (2015). Incidence, impact, and risk factors of adverse events in thoracic and lumbar spine fractures: an ambispective cohort analysis of 390 patients. Spine J. 15, 629-637.

8. Wilson, J.R., Grossman, R.G., Frankowski, R.F., Kiss, A., Davis, A.M., Kulkarni, A. V, Harrop, J.S., Aarabi, B., Vaccaro, A., Tator, C.H., Dvorak, M., Shaffrey, C.I., Harkema, S., Guest, J.D., and Fehlings, M.G. (2012). A clinical prediction model for long-term functional outcome after traumatic spinal cord injury based on acute clinical and imaging factors. J. Neurotrauma 29, 2263-2271.

9. Scivoletto, G., Morganti, B., Ditunno, P., Ditunno, J.F., and Molinari, M. (2003). Effects on age on spinal cord lesion patients' rehabilitation. Spinal Cord 41, 457-464.

10. Fletcher, D.J., Taddonio, R.F., Byrne, D.W., Wexler, L.M., Cayten, G., Nealon, S.M., and Carson, W. (1995). Incidence of acute care complictions in vertebral column fracture patients with and without spinal cord injury. Spine 20, 1136-1146.

11. Bourassa-Moreau, E., Mac-Thiong, J.M., Ehrmann Feldman, D., Thompson, C., and Parent, S. (2013). Complications in acute phase hospitalization of traumatic spinal cord injury: does surgical timing matter? J. Trauma Acute Care Surg. 74, 849-854.

12. Cheung, A., Thorogood, N.P., Noonan, V.K., Zhong, Y., Fisher, C.G., Dvorak, M.F., and Street, J. (2013). Onset, risk factors, and impact of delirium in patients with traumatic spinal cord injury. J. Neurotrauma 30, 1824-1829.

13. Furlan, J.C., Krassioukov, A. V, and Fehlings, M.G. (2005). The effects of gender on clinical and neurological outcomes after acute cervical spinal cord injury. J. Neurotrauma 22, 368-381.

14. Chen, D., Apple, D.F., Jr., Hudson, L.M., and Bode, R. (1999). Medical complications during acute rehabilitation following spinal cord injury-current experience of the Model Systems. Arch. Phys. Med. Rehabil. 80, 1397-1401.

15. Boakye, M., Arrigo, R.T., Hayden Gephart, M.G., Zygourakis, C.C., and Lad, S. (2012). Retrospective, propensity score-matched cohort study examining timing of fracture fixation for traumatic thoracolumbar fractures. J. Neurotrauma 29, 2220-2225.

16. Grossman, R.G., Frankowski, R.F., Burau, K.D., Toups, E.G., Crommett, J.W., Johnson, M.M., Fehlings, M.G., Tator, C.H., Shaffrey, C.I., Harkema, S.J., Hodes, J.E., Aarabi, B., Rosner, M.K., Guest, J.D., and Harrop, J.S. (2012). Incidence and severity of acute complications after spinal cord injury. J. Neurosurg. Spine 17, Suppl, 119-128.

17. Waring, W.P., Biering-Sørensen, F., Burns, S., Donovan, W., Graves, D., Jha, A., Jones, L., Kirshblum, S., Marino, R., Mulcahey, M.J., Reeves, R., Scelza, W.M., Schmidt-Read, M., and Stein, A. (2010). 2009 review and revisions of the International Standards for the Neurological Classification of Spinal Cord Injury. J. Spinal Cord Med. 33, 346-352.

18. Dimar, J.R., Fisher, C., Vaccaro, A.R., Okonkwo, D.O., Dvorak, M., Fehlings, M., Rampersaud, R., and Carreon, L.Y. (2010). Predictors of complications after spinal stabilization of thoracolumbar spine injuries. J. Trauma 69, 1497-1500.

19. Krassioukov, A.V., Furlan, J.C., and Fehlings, M.G. (2003). Medical co-morbidities, secondary complications, and mortality in elderly with acute spinal cord injury. J. Neurotrauma 20, 391-399.

20. Celani, M.G., Spizzichino, L., Ricci, S., Zampolini, M., and Franceschini, M. (2001). Spinal cord injury in Italy: a multicenter retrospective study. Arch. Phys. Med. Rehabil. 82, 589-596.

21. Demirel, G., Ylimaz, H., Gencosmanoglu, B., and Kesiktas, N. (1998). Pain following spinal cord injury. Spinal Cord 36, 25-28.

22. Cook, C., Tackett, S., Shah, A., Pietrobon, R., Browne, J., Viens, N., Richardson, W., and Isaacs, R. (2008). Diabetes and perioperative outcomes following cervical fusion in patients with myelopathy. Spine 33, E254-E260.

23. Kishi, Y., Robinson, R.G., and Forrester, A.W. (1995). Comparison between acute and delayed onset major depression after spinal cord injury. J. Nerv. Ment. Dis. 183, 286-292.

24. Haisma, J.A., van der Woude, L.H., Stam, H.J., Bergen, M.P., Sluis, T.A., Post, M.W., and Bussmann, J.B. (2007). Complications following spinal cord injury: occurrence and risk factors in a longitudinal study during and after inpatient rehabilitation. J. Rehabil. Med. 39, 393-398.

25. Verschueren, J.H., Post, M.W., de Groot, S., van der Woude, L.H., van Asbeck, F.W., and Rol, M. (2011). Occurrence and predictors of pressure ulcers during primary in-patient spinal cord injury rehabilitation. Spinal Cord 49, 106-112.

26. Street, J.T., Thorogood, N.P., Cheung, A., Noonan, V.K., Chen, J., Fisher, C.G., and Dvorak, M.F. (2013). Use of the Spine Adverse Events Severity System (SAVES) in patients with traumatic spinal cord injury. A comparison with institutional ICD-10 coding for the identification of acute care adverse events. Spinal Cord 51, 472-476.

27. World Health Organization. (1992). International Statistical Classification of Diseases and Related Health Problems. Tenth Revision. (ICD-10). World Health Organization: Geneva, Switzerland.

28. Noonan, V.K., Kwon, B.K., Soril, L., Fehlings, M.G., Hurlbert, R.J., Townson, A., Johnson, M., and Dvorak, M.F. (2012). The Rick Hansen Spinal Cord Injury Registry (RHSCIR): a national patientregistry. Spinal Cord 50, 22-27.

29. Glennie, R.A., Noonan, V.K., Fallah, N., Park, S.E., Thorogood, N.P., Cheung, A., Fisher, C.G., Dvorak, M.F., and Street, J.T. (2014). Reliability of the spine adverse events severity system (SAVES) for individuals with traumatic spinal cord injury. Spinal Cord 52, 758763.

30. Aito, S. (2003). Complications during the acute phase of traumatic spinal cord lesions. Spinal Cord 41, 629-635.

31. Schoenfeld, A.J., Ochoa, L.M., Bader, J.O., and Belmont, P.J. Jr. (2011). Risk factors for immediate postoperative complications and mortality following spine surgery: a study of 3475 patients from the National Surgical Quality Improvement Program. J. Bone Joint Surg. Am. 93, 1577-1582.

32. Marin, J., Nixon, J., and Gorecki, C. (2013). A systematic review of risk factors for the development and recurrence of pressure ulcers in people with spinal cord injuries. Spinal Cord 51, 522-527.

33. Mody, L., and Juthani-Mehta, M. (2014). Urinary tract infections in older women: a clinical review. JAMA 311, 844-854.

34. Crutcher, C.L. II, Ugiliweneza, B., Hodes, J.E., Kong, M., and Boakye, M. (2014). Alcohol intoxication and its effects on traumatic spinal cord injury outcomes. J. Neurotrauma 31, 798-802.

35. Witlox, J., Eurelings, L.S., de Jonghe, J.F., Kalisvaart, K.J., Eikelenboom, P., and van Gool, W.A. (2010). Delirium in elderly patients and the risk of postdischarge mortality, institutionalization, and dementia: a meta-analysis. JAMA 304, 443-451.

36. Girard, T.D., Jackson, J.C., Pandharipande, P.P., Pun, B.T., Thompson, J.L., Shintani, A.K., Gordon, S.M., Canonico, A.E., Dittus, R.S., Bernard, G.R., and Ely, E.W. (2010). Delirium as a predictor of longterm cognitive impairment in survivors of critical illness. Crit. Care Med. 38, 1513-1520.

37. Brown, T.M., and Boyle, M.F. (2002). Delirium. BMJ 325, 644-647.

38. Steiner, L.A. (2011). Postoperative delirium. Part 2: detection, prevention and treatment. Eur. J. Anaesthesiol. 28, 723-732.

39. Marcantonio, E.R., Goldman, L., Mangione, C.M., Ludwig, L.E., Muraca, B., Haslauer, C.M., Donaldson, M.C., Whittemore, A.D., Sugarbaker, D.J., Poss, R., et al. (1994). A clinical prediction rule for delirium after elective noncardiac surgery. JAMA 271, 134-139. 
40. Tolppanen, A.-M., Koponen, M., Tanskanen, A., Lavikainen, P., Sund, R., Tiihonen, J., Hartikainen, S., and Taipale, H. (2016). Antipsychotic use and risk of hospitalisation or death due to pneumonia in persons with and without Alzheimer disease. Chest 150, 1233-1241.

41. Ahmedani, B.K., Solberg, L.I., Copeland, L.A., Fang-Hollingsworth, Y., Stewart, C., Hu, J., Nerenz, D.R., Williams, L.K., CassidyBushrow, A.E., Waxmonsky, J., Lu, C.Y., Waitzfelder, B.E., OwenSmith, A.A., Coleman, K.J., Lynch, F.L., Ahmed, A.T., Beck, A., Rossom, R.C., and Simon, G.E. (2015). Psychiatric comorbidity and 30-day readmissions after hospitalization for heart failure, AMI, and pneumonia. Psychiatr. Serv. 66, 134-140.

42. Wałaszek, M., Kosiarska, A., Gniadek, A., Kołpa, M., Wolak, Z., Dobroś, W., and Siadek, J. (2016). The risk factors for hospital-acquired pneumonia in the Intensive Care Unit. Przegl. Epidemiol. 70, 15-20.

43. DeVivo, M.J., Kartus, P.L., Stover, S.L., Rutt, R.D., and Fine, P.R. (1989). Cause of death for patients with spinal cord injuries. Arch. Intern. Med. 149, 1761-1766.

44. Sopena, N., Heras, E., Casas, I., Bechini, J., Guasch, I., Pedro-Botet, M.L., Roure, S., and Sabrià, M. (2014). Risk factors for hospitalacquired pneumonia outside the intensive care unit: a case-control study. Am. J. Infect. Control 42, 38-42.

45. Santos, A., Gurling, J., Dvorak, M.F., Noonan, V.K., Fehlings, M.G., Burns, A.S., Lewis, R., Soril, L., Fallah, N., Street, J.T., Bélanger, L., Townson, A., Liang, L., and Atkins, D. (2013). Modeling the patient journey from injury to community reintegration for persons with acute traumatic spinal cord injury in a Canadian centre. PLoS One 8, e72552.

46. Burke, D., Fullen, B.M., Stokes, D., and Lennon, O. (2016). Neuropathic pain prevalence following spinal cord injury: A systematic review and meta-analysis. Eur. J. Pain e905.

47. Negraeff, M., Umedaly, H., Belanger, L.M., Dvorak, M.F., Townson, A.F., Prince, J., Shen, T., Park, S.E., and Noonan, V.K. (2014). Development of a clinical protocol to screen, diagnose and manage neuropathic pain in patients with traumatic SCI in an acute care setting. Presented at the American Spinal Injury Association 2014 Annual Scientific Meeting, San Antonio, TX.

Address correspondence to:

Travis E. Marion, MD, MSc, FRCSC

Department of Orthopaedics

Vancouver Spine Surgery Institute University of British Columbia

818 West 10th Avenue

Vancouver, British Columbia

V5Z 1 M9 Canada

E-mail: travismarion@gmail.com 